\title{
Examining the Role of Federal Adult Education Funding in Adult Literacy Education
}

Judy Mortrude, World Education, Inc.

First, Steve Reder is right. No one in the field of adult education is going to argue against Steve's conception of skill needs across the length and breadth of adult life. And certainly no one is going to argue against the need for more resources over and above the perpetually starved federal Workforce Innovation and Opportunity Act (WIOA) system to fund Steve's conceptual framework.

Beyond agreeing, I do think it is helpful to examine the role of federal adult education funding inside the lifelong and life-wide educational framework as both a way to value federally funded adult education programs and services AND a way to imagine the other funds, programs, and services needed to provide for skills needs across the length and breadth of life.

Lifelong learning in its platonic ideal would be a high-quality, fully accessible continuum of early childhood education, elementary and secondary school, postsecondary undergraduate and graduate schools and continued upskilling opportunities as digital displacement changes jobs and the pace of change in the digital economy leaves the knowledge economy behind. Unfortunately, quality universal early education is far from a reality in the United States, and the recent Programme for International Student Assessment again demonstrates that our elementary and secondary education systems need strategic investment and redesign to serve students better. College for all is a common rallying cry, but who gets what in the world of postsecondary education is largely still determined by income and race.

Adult basic education's role, from the beginning, has been about serving people with foundational skill needs. Except for highly skilled immigrants (now welcomed into WIOA as a target population via the Integrated English Literacy \& Civics Education program), adult education participants are generally those failed by their public education system, whether here in the United States, in a home country, or in displacement.

Adult education as part of a broader safety net of social services catches some few (by no means all) people who have fallen off that lifelong learning path at some point. Some states limit adult education programs to serving only those without a high school diploma or equivalent, but very clearly foundational skill need is not defined by the secondary credential. The federal eligibility criterium is simply a demonstrated educational need.

The original federal investment in adult education came as part of the Great Society movement, part of the war on poverty. In 1966, the goal of 
adult education was to help people achieve an 8th grade level of education - a level needed for selfsufficiency in the economy of the time. Over time, as that standard changed, adult education became more about high school completion, and now adult education has more focus on college and career readiness.

Federal educational investments are about equity, about delivering certain program models/services to specific targeted populations, (pretty much) regardless of your state's governor and lawmakers. State investments, of course, can do a whole lot more. In 1856, California brought us the first adult school which provided English language learning to communities with foreign born populations. Over time, California invested to create a large system of comprehensive adult schools. Then California's adult education investment was nearly "flexed" out of existence during lean budget times when local educational agencies opted to use the state funds to keep K-12 systems afloat. (The 'deservingness' question looms large over adult education - who deserves educational investment? Didn't those high school dropouts have their chance? Shouldn't those immigrants already know English before coming here?) California's adult education system has now roared back to life with an annual investment nearly matching that of the federal investment across all 50 states and territories. Yet the federal adult education funds and their required state maintenance of effort funds kept classrooms open during those lean times.

Steve warns against the very real danger of a society that "values individuals only as economic actors." The focus on economic outcomes for federal investment, the search for an elusive "return on investment," can certainly skew decisions and influence services offered in communities. However, to create at minimum a baseline of basic adult education services across the 50 states and territories, I am grateful to have a federal investment that comes with eligibility criteria, program service models, and performance accountability. Having said that, I believe our field has been far too cautious in using the tools inside WIOA to shape a program to benefit our learners. As a moonlighting evening GED teacher in the 1980s, I entered a field blossoming with adult education theory: Malcolm Knowles codified his andragogy framework; Thomas Stitch detailed Functional Context Education; and Equipped for the Future helped us think about providing the services and settings needed to help adult learners not only survive but also thrive and strive.

Unfortunately, during the years under the Workforce Investment Act (WIA), we proved the maxim of "what gets measured is what gets done" and became way too good at meeting the federal WIA performance targets based on standardized test gain. Educational Function Level (EFL) gain became the goal. Thanks to philanthropic investment and federal innovation funds, we also innovated and experimented and helped shape WIOA, the law that would allow us to break out of pretest/posttest as the only valuable form of learning gain. Yet, because of the measurement systems established under WIA, test gains still dominate.

It is time for our field to seriously revisit how we demonstrate skill gain. In the world of multiple measures, when people don't even need to take a standardized test to go to graduate school, our students can only prove they are learning by scoring a few more points. Most WIOA Title II funded programs are still living and dying on EFL. Why? It's the only WIOA performance measure that is a "negotiated performance target" - a level set by negotiation between the U.S. Department of Education and state adult education offices, but other performance measures 
are being collected and could become the focus of our work. For example, WIOA's Measurable Skill Gain contains five ways to measure progress, including training milestones or passing an industry exam as well as transition into postsecondary education. While WIOA partners are now collecting these measures, within limited context and with great variability, the measures are not what "counts" in a states' performance report with the federal agencies.

As Steve points out, outcome measurement systems are costly to implement and very slow to adapt. The WIOA outcomes could but haven't adjusted to innovative service delivery models focused on communities with the greatest need for public services. WIOA's precursor, the WIA, had locked the public workforce development system into a labor exchange model - a triage model rewarded for job placement and job retention - keeping the same job for six months. WIOA offers a career pathway approach - a wellness model - with exit measures focused on educational credential attainment and employment.

Unfortunately, just as adult education continues to focus on EFL, the public workforce system as a whole is still very much focused on short term activity rather than providing the intensity and quality of education, training, and other services that can make a longer-term impact on a participant's life.

The promise of shared accountability in a coenrollment environment, where partners across a community WIOA partnership could dually enroll an individual, leverage one another's staff and resources to provide services within their area of expertise, and each take credit for all performance outcomes an individual achieves regardless of "who paid for what," hasn't been realized. No one is studying WIOA outcomes yet because we haven't fully turned on the complement of WIOA measures mapped against the list of population characteristics (demographics, barriers) that would help us see if our equity investment is moving the needle for those who need us most. A well-kept secret in WIOA performance is the regression model, designed to reward states and programs that serve individuals with the most "barriers." While riddled with deficit language, the concept is worth trying. What would it be like to intentionally choose to recruit and serve people in our communities that need our services the most?

But even if we fully operationalized the career pathway vision inside WIOA, it would still only provide a system focused on education for college and career readiness and advancement. We know that's not an exhaustive way to measure adult education's impact. Just as no program should live exclusively on WIOA Title II funds. It's not healthy for the program which will suffer greatly at whims (government shutdowns; draconian federal budget cuts); and it isn't healthy to have all your performance measures dictated by one fund. We need other measurements supported by other funds.

The ALLIES (Alliance for Language Learners' Integration, Education, and Success) Immigrant Integration Framework provides eight goals areas with corresponding metrics, designed to measure two-way integration that benefits both the immigrant and the receiving community. This life-wide conception includes economic security, educational and career advancement as well as health and well-bring, providing for children and family, and participation in civic and community life. Imagine the power of having this vision at the heart of adult education - not just for immigrants but for all of us as we seek a revitalized civic discourse and equitable economies. This would require adult educators to think expansively about their partnerships and their services and the way they frame their own value in their communities. 
Last year's Minds that Move Us Career Pathways Challenge illustrates another way of defining our value. Johan Uvin's Institute for Education Leadership delivered a rapid year of program development culminating in an August 2019 Adult Career Pathway Festival featuring 10 teams pitching their solutions to identified community needs. The teams didn't define their value in terms of educational functioning level gain or even credential attainment, but instead put the focus on adult education as a solution to tangible community problems, e.g.: Latinx injuries and deaths on construction sites; aging community members in need of home care; historic, systemic trauma impacting individuals and community systems. There is so much to be learned from this way of reframing adult education's impact.

Perhaps if we can see our work within that larger integration and community context, we will be ready to capitalize with partners on new investment. Federal bills continue to percolate in Congress, including the Digital Equity Act which would support state planning and investment in digital infrastructure and skills, the SKILLS Act which would establish a workforce retraining entitlement for working learners; and the New Deal for New Americans bill that lays out a positive, pro-active vision for immigrant integration across a range of issue areas, including establishing a new $\$ 100 \mathrm{M}$ English as a Gateway to Integration grant program and a new $\$ 100 \mathrm{M}$ Workforce Development and Prosperity grant program that would support Integrated Education and Training models. At the state level, governors are supporting Future of Work conversations that need adult education's voice and at the local level, someone in your community right now is discussing Census 2020 activities where you can play a role in delivering resources and representation for your community.

Finally, our solutions need to be driven by our community needs. Any adult educator will tell you that the best part of the job is working with adult learners whose tenacity and curiosity inspire us daily. Working with the people in our classrooms and communities, we can and must develop new practices, measures, partners, and funding opportunities to broaden our work and lengthen our impact. 